\title{
Theoretical implication of reversals of the ozone weekend effect systematically observed in Japan
}

\author{
A. Kannari ${ }^{1}$ and T. Ohara ${ }^{2}$ \\ ${ }^{1}$ Independent researcher, NIES visiting researcher, Tokyo, Japan \\ ${ }^{2}$ National Institute for Environmental Studies (NIES), Tsukuba, Japan \\ Received: 20 May 2009 - Published in Atmos. Chem. Phys. Discuss.: 8 June 2009 \\ Revised: 12 May 2010 - Accepted: 17 July 2010 - Published: 23 July 2010
}

\begin{abstract}
Systematic changes of the ozone weekend effect are found over broad areas of Japan. These changes are characterized by (1) spatial reversals from a weekend increase in the vicinity of huge precursor source areas to a weekend decrease in the surrounding rural areas, and (2) temporal reversals from a weekend increase under relatively unsuitable meteorological conditions for ozone formation to a weekend decrease under relatively suitable conditions. We developed a simple numerical advection-reaction model to explain the relationship between the duration of advection and the supplied solar energy, which causes the daily maximum ozone concentration to be lower near the precursor source. Ozone isopleth diagrams for individual advection durations (equivalent to the distance from the source) for a wide range of initial precursor conditions show that both VOC-limited and $\mathrm{NO}_{\mathrm{x}}$-limited regimes exist for each advection duration, but the area of $\mathrm{NO}_{\mathrm{x}}$-limited regime becomes dominant as the advection duration increases because of the increased exposure of the air mass to solar energy. For given initial VOC and $\mathrm{NO}_{\mathrm{x}}$ concentrations, the area remote from the source becomes a $\mathrm{NO}_{\mathrm{x}}$-limited regime even if the precursor source area is in the VOC-limited regime. The rate of reduction of weekend emissions of $\mathrm{NO}_{\mathrm{x}}$ is larger than that of VOC, causing a weekend increase in ozone inside an area of VOClimited regime near the source, but a weekend decrease in remote areas with a $\mathrm{NO}_{\mathrm{x}}$-limited regime. The boundary between these two ozone formation regimes depends on meteorological conditions: when sunlight intensity and temperature are relatively low, the change from a VOC-limited to a $\mathrm{NO}_{\mathrm{x}}$-limited regime occurs at a point more remote from the source than when they are relatively high, which causes a prevailing ozone weekend increase over a wide geographical area on days with lower ozone potential. Therefore, obser-
\end{abstract}

Correspondence to: A. Kannari (kannari.akiyoshi@circus.ocn.ne.jp) vations of ozone weekend changes can be interpreted in light of the theoretical implications of our model; they can be used for determination of ozone formation regimes, which change in different locations and under different meteorological conditions.

\section{Introduction}

Many observational studies have reported weekend ozone concentration changes in large cities and their surroundings over the past 30 years. The most remarkable and frequently observed phenomenon is a rise in ozone concentrations on the weekend despite a weekend decrease in the emissions of ozone precursors (the "ozone weekend effect", OWE). The OWE has been observed in many cities around the world since the 1970s (e.g., Cleveland et al., 1974; Elkus and Wilson, 1977; Altshuler et al., 1995; and many other studies cited by Stephens et al., 2008). The most probable, though not yet well established, cause of the OWE among the six hypotheses suggested by the California Air Resource Board is a larger reduction in $\mathrm{NO}_{\mathrm{x}}$ emissions than in emissions of nonmethane volatile organic compounds (NMVOCs) in a VOClimited ozone formation regime (Heuss et al., 2003).

Two recent findings concerning the ozone weekend effect are particularly important. First, a spatial reversal of the OWE, from a weekend increase near the precursor source area to a weekend decrease in downwind rural areas, has been reported (Blanchard and Fairley, 2001; Murphy et al., 2006, 2007). Second, a temporal reversal of the OWE may occur at a single observation point, depending on the meteorological conditions: a weekend increase under relatively unsuitable meteorological conditions for ozone formation reverses to a weekend decrease under more suitable conditions (higher solar intensity and higher temperatures) (Brönnimann and Neu, 1997; Paschalidou and Kassomenos, 2004). These findings suggest that weekend changes in ozone concentrations reflect

Published by Copernicus Publications on behalf of the European Geosciences Union. 
a) $\mathrm{NOx}_{5-15 \mathrm{~h}}$

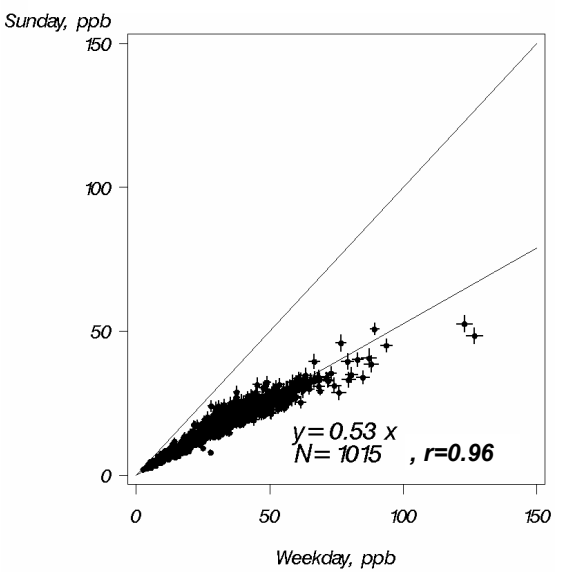

b) $\mathrm{NMVOC}_{5-15 \mathrm{~h}}$

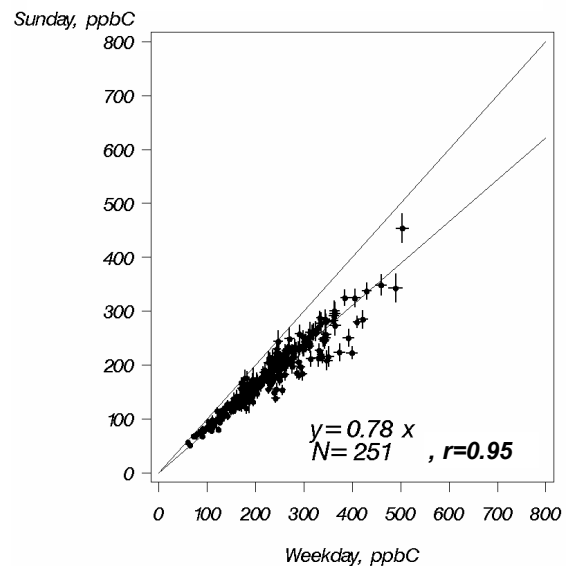

c) $\mathrm{VOC} / \mathrm{NOx}, 5-15 \mathrm{~h}$

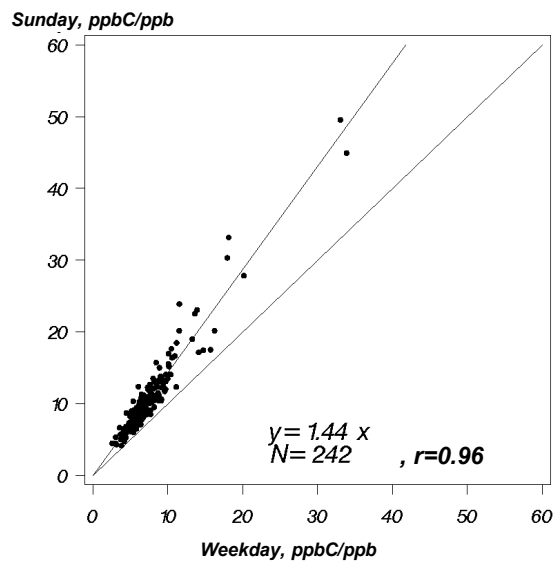

Fig. 1. Comparison of precursor concentrations between weekdays and Sundays measured from 05:00 to 15:0 LT during 1999-2004. Bars in (a) and (b) indicate the 95\% confidence limits of the mean values.

dynamic phenomena closely related to chemical transport mechanisms. Though these studies reported only fragmented observations on the spatial or temporal reversal of the OWE, Kannari (2006a, b) studied observational data obtained by continuous monitoring in two metropolitan areas, Tokyo and Osaka-Kyoto, Japan, and found by a detailed statistical analysis both spatial and temporal systematic reversals of the OWE. The present study extends this analysis of ozone weekend changes to larger areas in Japan. Moreover, Kannari and Ohara (2009) recently developed a simple theoretical model to concisely explain the mechanisms behind these systematic OWE reversals. According to their model, the ozone formation regime changes with both distance from the precursor source and meteorological conditions (e.g., sunlight intensity), and this regime change causes the OWE reversals. In this paper, we discuss the usefulness of observations of OWE reversals for determination of ozone formation regimes in light of the theoretical implications of our model.

\section{Observed reversals of the ozone weekend effect}

\subsection{Observation data}

In a cooperative research project, the National Institute for Environmental Studies and the many local governmental institutes for environmental studies in Japan have developed a historical data archive of hourly monitored data consisting of the concentrations of many air pollutants and observed meteorological parameters for 1972-2004. In this study, we used the hourly data for $\mathrm{O}_{3}, \mathrm{NO}+\mathrm{NO}_{2}\left(\mathrm{NO}_{\mathrm{x}}\right)$, NMHC (hereafter VOC, because the measured concentrations in the data archive include some oxygenated compounds), and surface meteorological parameters (wind, temperature, humidity, and solar radiation). We defined a valid day of ozone measurement as one in which measurements were obtained over 12 or more hours between 05:00 and 20:00 local time (LT). Similarly, we defined valid days of $\mathrm{NO}_{\mathrm{x}}$ and VOC measurement those with measurements available for 20 or more hours of the day. We defined valid monitoring sites as those with 250 or more valid measurement days annually. For our analyses, we used monitoring sites on the Japanese mainland (Honshu) and on Shikoku and Kyushu islands judged to be valid in every year from 1999 to 2004: 899 monitoring sites for $\mathrm{O}_{3}, 251$ sites for $\mathrm{VOC}$, and 1015 sites for $\mathrm{NO}_{\mathrm{x}}$.

\subsection{Weekend changes in precursor concentrations}

We classified all days as weekdays (Monday to Friday, excluding national holidays), Saturdays, or Sundays and compared mean daytime (05:00-15:00 LT) concentrations of $\mathrm{NO}_{\mathrm{x}}$ and VOC at the individual sites over the entire study period (1999-2004) between weekdays and Sundays (Fig. 1). Because Saturday is not a full holiday in Japan, precursor concentrations on Saturdays fall between those for weekdays and Sundays (data not shown). Mean daytime concentrations of $\mathrm{NO}_{\mathrm{x}}$ decreased by almost $50 \%$ on Sundays, whereas VOC concentrations decreased by only about $20 \%$. Therefore, the VOC/NO $\mathrm{Na}_{\mathrm{x}}$ ratio significantly increased on Sundays by more than $40 \%$ (Fig. 1c). These findings agree with results reported for the United States (Blanchard and Fairley, 2001; Pun and Seigneur, 2003; Fijita et al., 2003). We consider this increase in $\mathrm{VOC} / \mathrm{NO}_{\mathrm{x}}$ to be a key factor in ozone weekend changes. The main cause of this weekend imbalance between changes in $\mathrm{NO}_{\mathrm{x}}$ and VOC in Japan is that most heavy-duty diesel trucks, which emit large amounts of $\mathrm{NO}_{\mathrm{x}}$ but not very large amounts of VOC, do not operate on Sundays in urban areas. 
a)

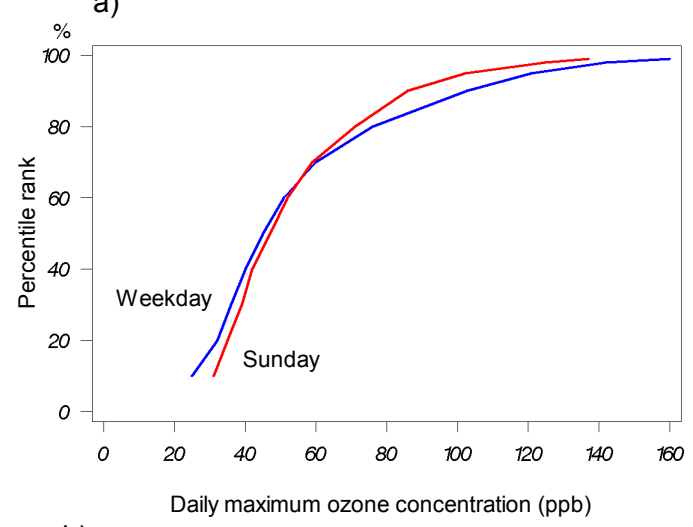

b)

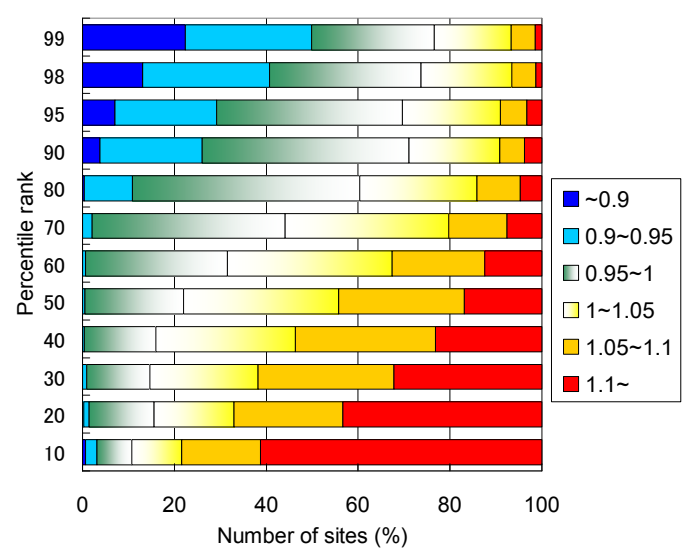

Fig. 2. (a) An example of cumulative frequency curves of daily maximum ozone concentrations for weekdays and Sundays, allowing comparison of values at the same percentile rank of $\mathrm{O}_{3 \max }$. (b) Number of sites showing the ozone weekend effect, indicated by the ratio of the daily maximum concentration on Sundays to that on weekdays (colored scale), according to the percentile ranking of the ozone concentration. Total number of sites $=899$, with data available for 1999-2004 from 36 prefectures in mainland Japan (Honshu) and Shikoku and Kyushu islands.

\subsection{Reversals of the ozone weekend effect}

We compared cumulative frequency curves of the daily maximum ozone concentration $\left(\mathrm{O}_{3 \max }\right)$ at each monitoring site between weekdays and Sundays (Fig. 2a). By comparing $\mathrm{O}_{3 \max }$ between weekdays and Sundays at the same percentile rank, we ensured that we were comparing values under similar meteorological conditions (see Fig. 4c and d). Weekend changes in $\mathrm{O}_{3 \max }$ at all 899 monitoring sites are shown in Fig. 2b. The ratio of the weekend (Sunday) $\mathrm{O}_{3 \max }$ to the weekday value (colored scale) changes remarkably with the percentile rank; namely, most monitoring sites show a change from a weekend increase at lower percentile ranks to a weekend decrease at higher percentile ranks.

To investigate the cause of this systematic change in the ozone weekend effect, we examined the geographical dis- tribution of Sunday/weekday $\mathrm{O}_{3 \max }$ ratios at each percentile rank. Figure 3a-d shows the example of the spatial structure of the OWE changes under the meteorological conditions for the 70th to 98th percentile ranks of $\mathrm{O}_{3 \max }$. For comparison, the spatial distributions of $\mathrm{NO}_{\mathrm{x}}$ and $\mathrm{VOC}$ emission fluxes from 06:00 to 15:00 LT in July 2000 (Kannari et al., 2007) are shown in Fig. 3e and f. The VOC emission flux values include the flux from biogenic sources. Our study area included three metropolitan areas, Tokyo, Nagoya, and OsakaKyoto, each of which is an area of very high precursor emissions. At percentile ranks below the 70th percentile, only $2 \%$ of the monitoring sites showed a weekend decrease of more than 5\% in $\mathrm{O}_{3 \max }$ (Figs. 2b and 3a), but at the 80th percentile rank, areas remote from the high precursor emission sources showed a weekend ozone decrease (Fig. 3b); moreover, at the 90th and 98th percentile ranks even areas near the precursor source areas showed a weekend decrease (Fig. 3c, d).

Both a spatial structure of the ozone weekend effect related to distance from the source area, as described by Blanchard and Fairley (2001) and Murphy et al. (2006), and systematic changes in the weekend difference in relation to meteorological conditions, as reported by Brönnimann and Neu (1997) and Paschalidou and Kassomenos (2004), are apparent in Figs. 2 and 3. We therefore investigated emissions and meteorological conditions in greater detail in the Tokyo Metropolitan Area (TMA in Fig. 3a) (Fig. 4). We defined the regional ozone level in the TMA on each day as the average of the mean $\mathrm{O}_{3 \max }$ in all $10 \mathrm{~km} \times 10 \mathrm{~km}$ grid cells in the area. Figure 4a shows the percentage of monitoring sites showing any weekend increase $(R>1.0)$ and a large weekend increase $(R>1.1)$, where $R=\mathrm{O}_{3 \max , \text { Sunday }} / \mathrm{O}_{3 \text { max }}$, weekday, in relation to the percentile rank of the regional ozone level. The number of sites showing a weekend increase dropped at higher regional ozone levels, consistent with the data shown in Fig. 2. Moreover, meteorological conditions (i.e., solar radiation and temperature) were clearly correlated with the percentile rank of the regional ozone concentration (Fig. 4c, d), suggesting that the reversals in the OWE as the ozone level increased were affected by changes in meteorological conditions, as has already been shown by Paschalidou and Kassomenos (2004).

Importantly, $\mathrm{VOC} / \mathrm{NO}_{\mathrm{x}}$ between 06:00 and 09:00 LT, calculated using data from the 180 sites monitoring both VOC and $\mathrm{NO}_{\mathrm{x}}$, showed a clear increase on Sundays relative to weekdays, and also gradually increased with the percentile rank of the regional ozone level (Fig. 4b).

In the TMA, when the regional ozone level is extremely high, the surface wind system changes between 09:00 and 10:00 LT from a weak land breeze to a sea breeze and then develops into a strong sea breeze, on both weekdays and Sundays (Fig. 5). Therefore, we inferred that the spatial reversals of the OWE shown in Fig. 3d occurred along the transport path from this large precursor source area, in a manner similar to the transport from the west coast to inland areas of central California shown by Blanchard and Fairley (2001). 

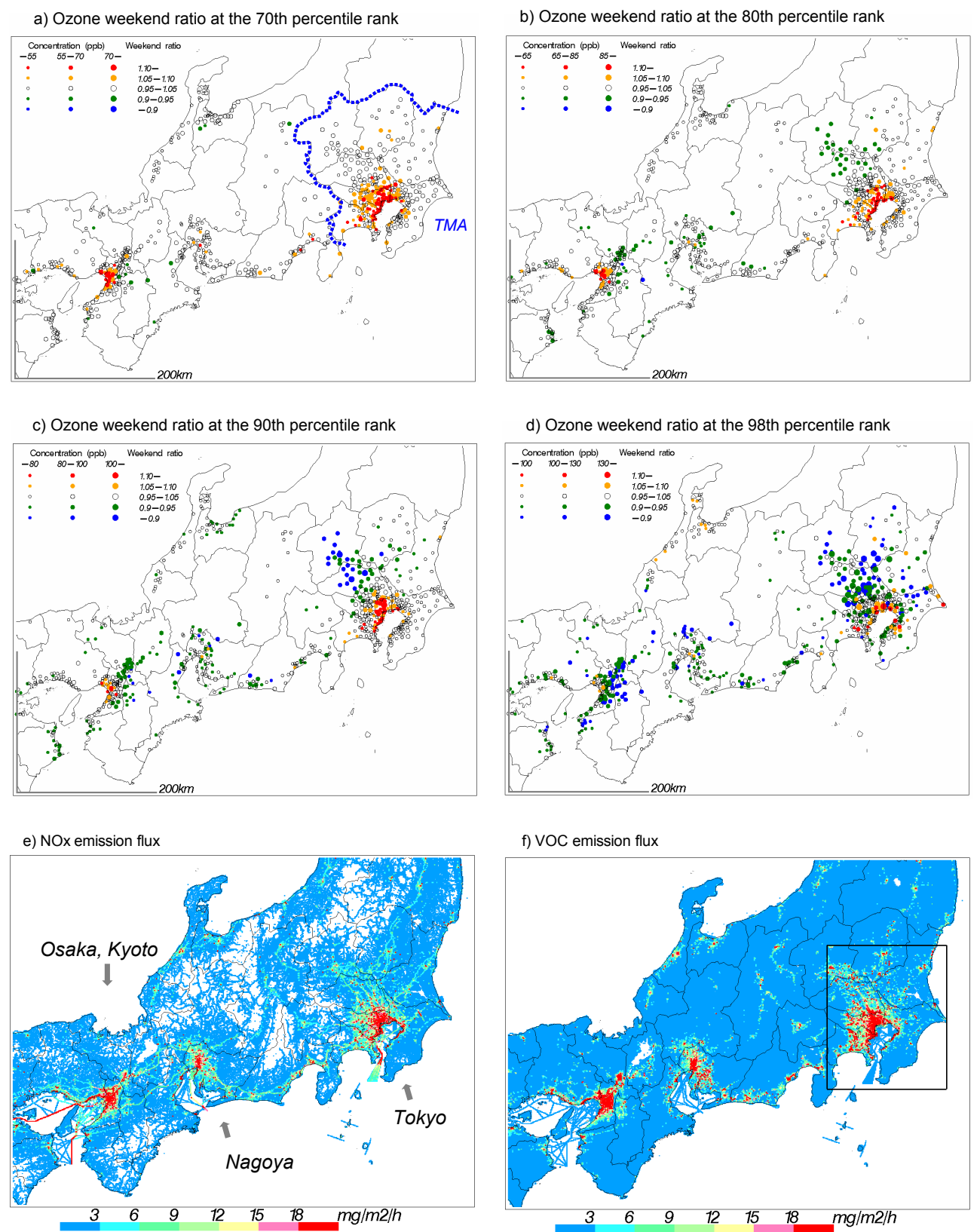

Fig. 3. (a)-(d) Spatial distributions of the ozone weekend ratio comparing ozone concentrations on Sundays to those on weekdays at the (a) 70th, (b) 80th, (c) 90th, and (d) 98th percentile rank of $\mathrm{O}_{3 \mathrm{max}}$. TMA, Tokyo Metropolitan Area. Panels (e) and (f) show the spatial distributions of mean $\mathrm{NO}_{\mathrm{x}}$ and VOC emission fluxes $\left(\mathrm{mg} / \mathrm{m}^{2}\right.$ per hour) for 06:00-15:00 LT in July 2000 (emission inventory EAGrid2000JAPAN; Kannari et al., 2007). Biogenic sources are included in the VOC emissions. Tokyo, Nagoya, and Osaka-Kyoto are each at the center of a high emission flux area. The rectangle in panel f) encloses the target area used for estimating the composition of emitted VOCs (see Table 1).

These indirect lines of evidence suggest that the reversals of the OWE shown in Figs. 2 and 3 essentially reflect spatial changes during chemical transport and are strongly affected by meteorological conditions. Kannari and Ohara (2009) explained the mechanism of spatial reversals of the OWE in relation to meteorological conditions by a very simple theoretical model. In the next section, we describe the main points of this model and its application to our data. 

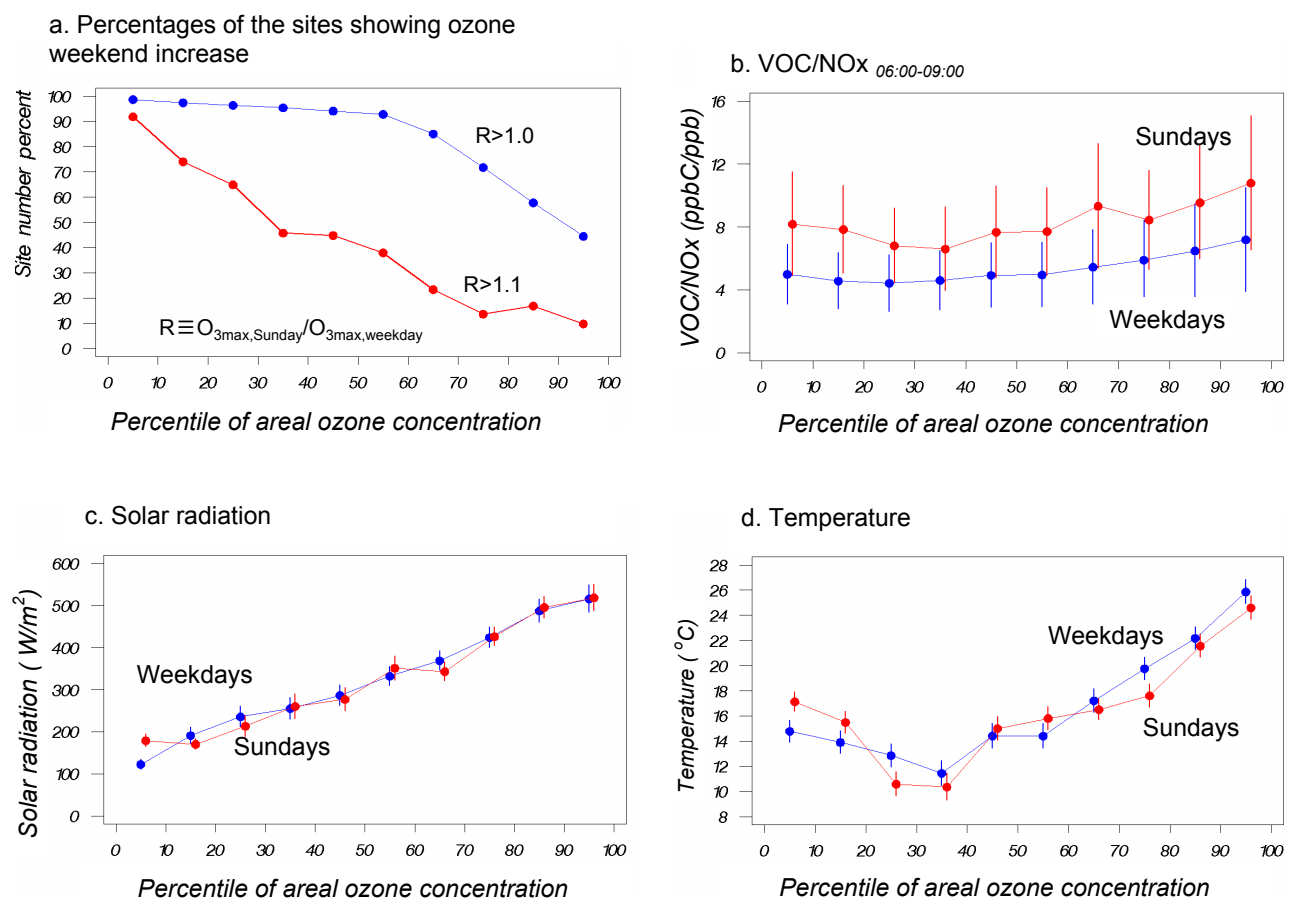

Fig. 4. Variation of parameters with the regional ozone concentration percentile rank in the TMA (see Fig. 3a) during 1999-2004. (a) Percentage of sites showing an ozone weekend increase among 308 monitoring sites. (b) Mean VOC/NO $\mathrm{X}_{\mathrm{x}}$ during 06:00-09:00 LT on weekdays and Sundays at 180 monitoring sites. (c) Mean solar radiation at 21 monitoring sites. (d) Mean temperature at 179 monitoring sites. In b), c) and d), the error bars show the standard deviation (SD).

a) 09:00 LT

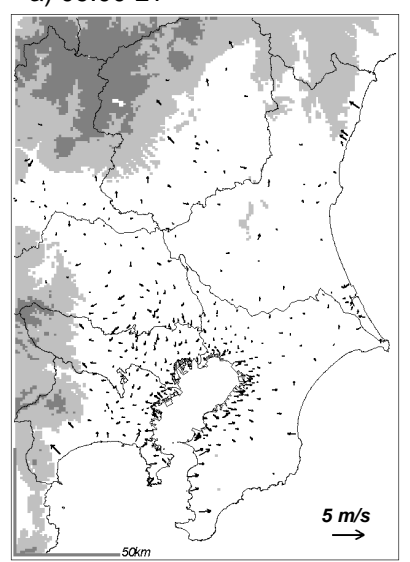

b) 15:00 LT

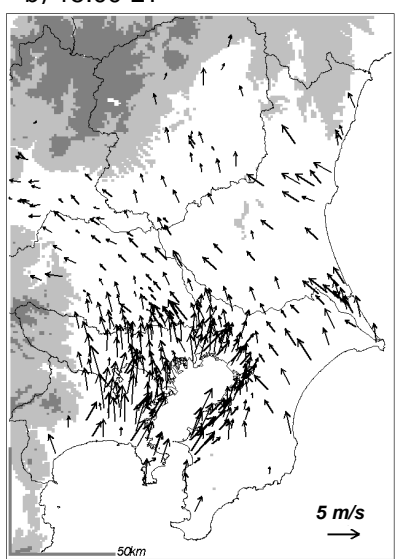

Fig. 5. Mean observed surface wind vectors at (a) 09:00 LT and (b) 15:00 LT on weekdays at the 95-100th percentile rank of the TMA ozone level during 1999-2004. Light (dark) gray areas indicate mountainous areas higher than $300 \mathrm{~m}(1000 \mathrm{~m})$. Features on Sundays are similar to those on weekdays.

\section{Analysis of reversals of the OWE based on ozone isopleth diagrams}

\subsection{Advection-reaction model}

It is well known that as an air mass is transported, there are two chemical regimes for ozone formation (Jacob, 1999; Jenkin, 2000). Though ozone formation in an air mass is governed by VOC-limited chemistry just after the air mass leaves an urban source area, during the air mass's transport to a remote area the regime ultimately becomes $\mathrm{NO}_{\mathrm{x}}$-limited as a result of the elimination of $\mathrm{NO}_{\mathrm{x}}$ by the reaction between $\mathrm{NO}_{2}$ and $\mathrm{OH}$. Moreover, similarity theory predicts that the regime boundary at a given time depends only on the ratio of initial VOC and $\mathrm{NO}_{\mathrm{x}}$ concentrations (e.g., Sillman, 1999). This Lagrangian basis regime change can easily be supposed to be related to the OWE reversals observed on the Eulerian basis geography. We introduce a simple model to investigate the mechanism of the OWE reversals by estimating chemical regime changes for $\mathrm{O}_{3 \max }$ formation in a Eulerian coordinate system.

This advection-reaction model, which calculates ozone concentrations in air masses continually arriving at a receptor point from a steady-state emission source, is based on a Lagrangian transport model, and for simplicity it excludes diffusion and deposition. The daily maximum ozone concentration $\left(\mathrm{O}_{3 \max }\right)$ is defined by the maximum value in the 


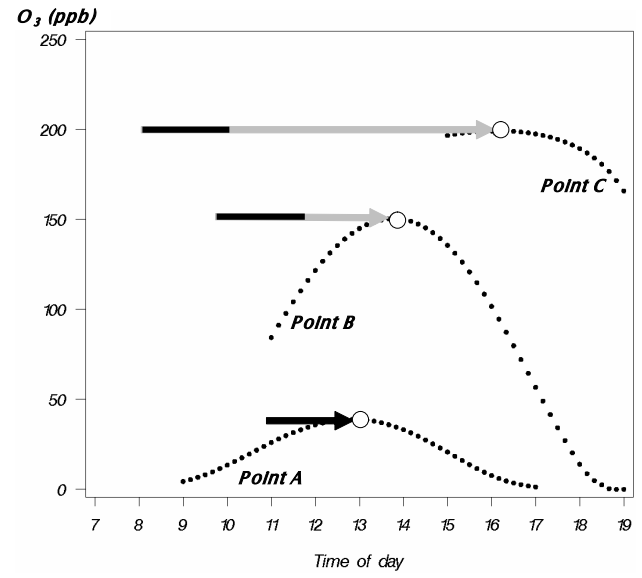

Fig. 6. Schematic diagram of time-dependent $\mathrm{O}_{3}$ concentrations calculated at points A (near the source, $D=2 \mathrm{~h}$ ), B (middle range, $D=4 \mathrm{~h}$ ), and $C$ (remote, $D=8 \mathrm{~h}$ ), by assuming a constant emission rate (beginning at 07:00 LT) and wind speed, with solar radiation and temperature dependent on the time of day. Arrows indicate the advection duration of the air mass bringing $\mathrm{O}_{3 \max }$. The length $L$ of the precursor source was assumed to be $2 \mathrm{~h}$ (indicated by the black parts of the arrows).

time series for each receptor point (Fig. 6). According to the Lagrangian model, an air mass originating at the upwind edge of a source area continues to acquire precursor gases at a constant rate in the source area, and reactions occur continuously during its advection from its start point to the receptor point, in both urban and rural areas. The normalized distance $(D)$ from the upwind edge of the source area is defined as $D=X / U$, where $X$ is the distance from the start point and $U$ is wind speed. The length of the source area is also defined by the passing duration $L(\mathrm{~h})$, assuming a uniform injection rate $q(\mathrm{ppb} / \mathrm{h})$ of precursors, and the supplied amounts of precursors are their initial concentrations, expressed as $q L$ (ppb). The most important parameters in the model are the daily changes in solar radiation and temperature; $\mathrm{O}_{3 \max }$ occurs at the time of day when solar radiation and temperature are highest during the advection (see Fig. 6).

For the model analysis, we used averaged diurnal patterns of meteorological conditions - namely, solar radiation, temperature, and humidity - over several percentile rank intervals of the TMA ozone level (e.g., Fig. 7), and used the carbon bond IV (CBIV) chemical reaction scheme (Gery et al., 1989). We estimated VOC compositions (Table 1) from source-specific emissions in August 2000 in the area enclosed by the rectangle in Fig. 3f, as reported in the emission inventory EAGrid2000-Japan (Kannari et al., 2007), and the speciation profiles for each source. VOC compositions may differ between weekdays and weekends, but because we did not have weekend emission inventory data except for road vehicles, we used the overall composition as indicated by the mean emission rates. The source length of the precursors
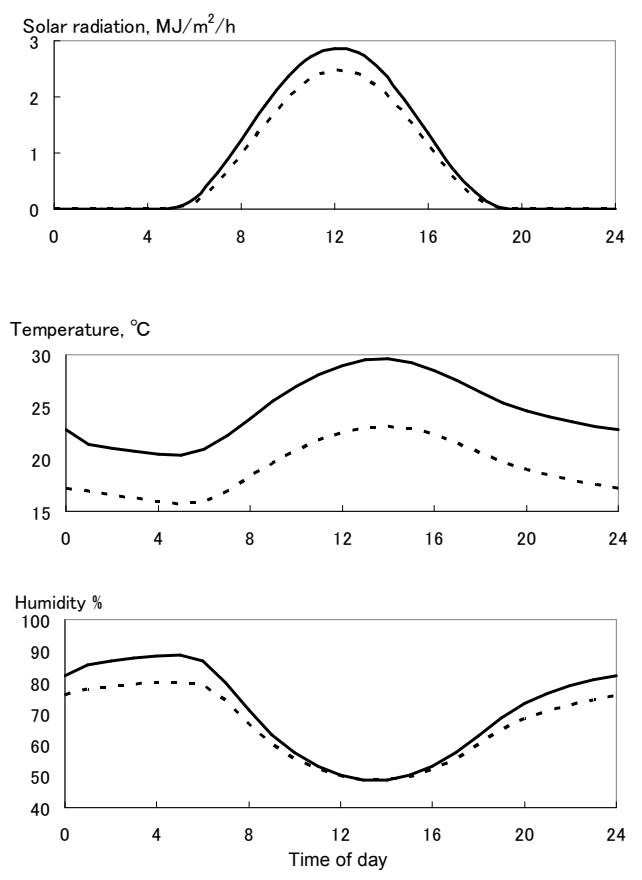

Fig. 7. Mean meteorological conditions for the 95-100th (solid lines) and the 75-80th (dashed lines) percentile rank intervals of $\mathrm{O}_{3 \max }$ in the TMA. Values are for weekdays, but those on Sundays are similar. Daytime water vapor concentrations (volume mixing ratios) are nearly constant $(2.1 \%$ for the $95-100$ th, and $1.4 \%$ for the 75-80th percentile rank interval).

was set to $L=2 \mathrm{~h}$, corresponding to about $20-40 \mathrm{~km}$ at wind speeds of 3-6 m/s. Because precursor emissions are very low before 07:00 LT in the TMA, we assumed constant emission rates beginning at this time. This constraint affects the $\mathrm{O}_{3 \max }$ only at extremely remote points with an advection duration (i.e., distance from the source) of over $10 \mathrm{~h}$. In the model, $\mathrm{NO}_{\mathrm{x}}$ is emitted as nitric oxide, $1 \mathrm{ppb}$ is used as the initial ozone concentration, and $10^{-13} \mathrm{ppb}$ as the initial concentration of all other species.

Examples of downwind $\mathrm{O}_{3 \max }$ distributions calculated by the model for meteorological conditions in the 95-100th percentile rank interval of TMA ozone levels are shown in Fig. 8a, for both a typical weekday initial concentration (symbol A) and a reduced Sunday initial concentration (symbol B) (based on data shown in Fig. 1). The rates of increase of $\mathrm{O}_{3 \max }$ with $D$ differ between A and B, causing a reversal of $\mathrm{O}_{3 \max }$ from $\mathrm{B}>\mathrm{A}$ to $\mathrm{A}>\mathrm{B}$ at $D=5.2 \mathrm{~h}$, like the observed reversals of the OWE. Reflecting the properties of the advection-reaction model, the occurrence time of $\mathrm{O}_{3 \max }$ $\left(T_{\max }\right)$ delays with $D$ by nearly $0.5 \Delta D$, as shown in Fig. 8b.

\section{2 $\mathrm{O}_{3 \max }$ isopleth diagrams}

By using the same calculations for initial concentrations of $\mathrm{VOC}_{0}=10-1000 \mathrm{ppbC}$ and of $\mathrm{NO}_{\mathrm{x}_{0}}=1-100 \mathrm{ppb}$, isopleth 

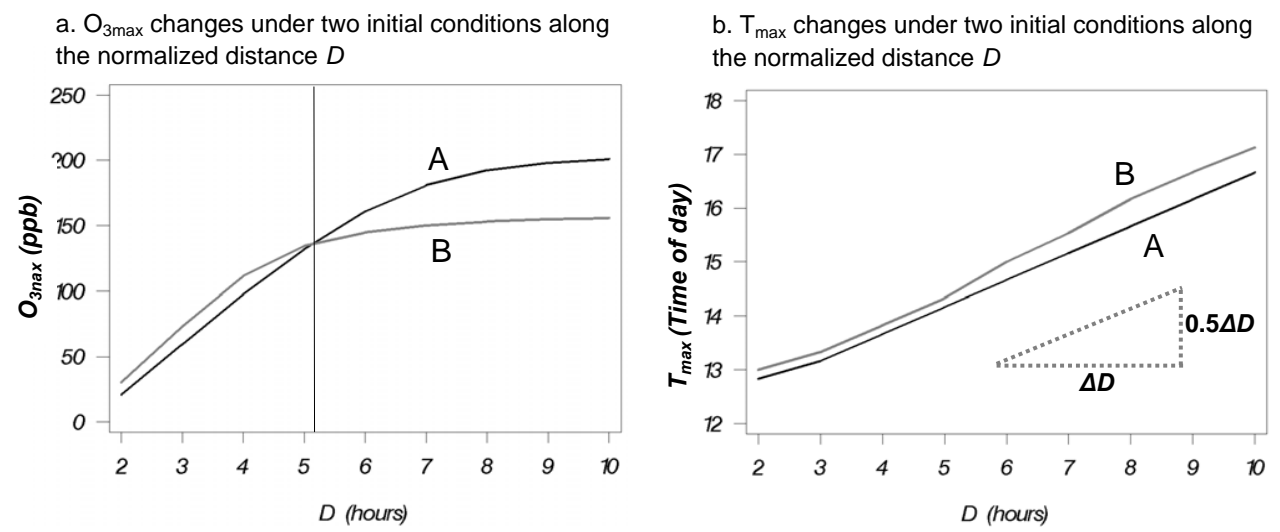

c. $\mathrm{O}_{3 \max }$ isopleths for $D=3 \mathrm{~h}$
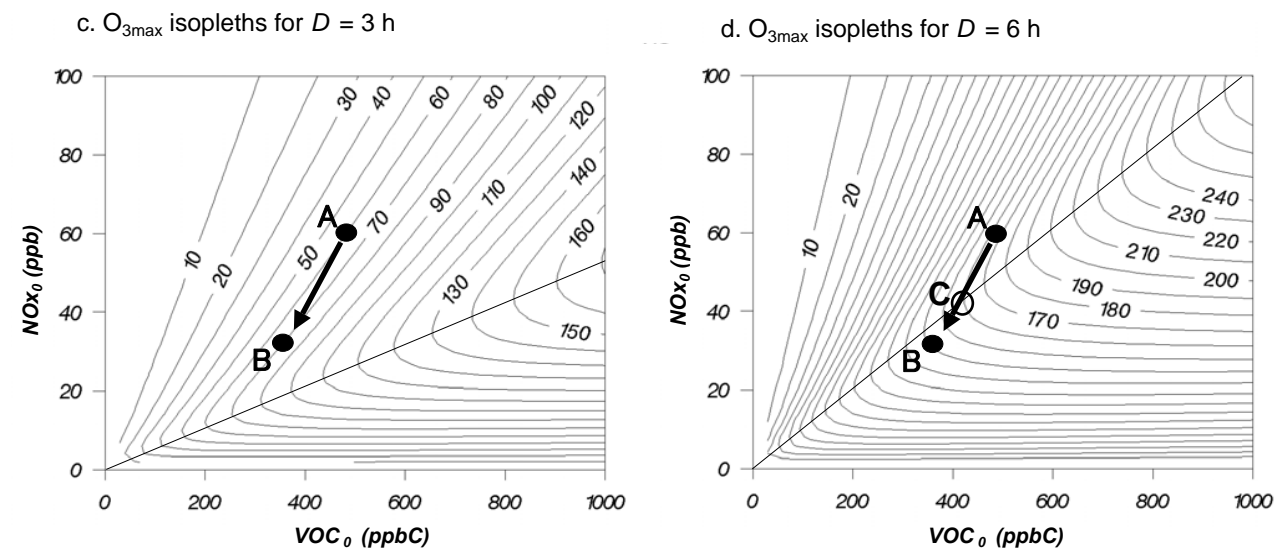

Fig. 8. (a) Examples of $\mathrm{O}_{3 \max }$ changes with downwind distance from sources $\mathrm{A}\left(\mathrm{NO}_{\mathrm{x} 0}=60 \mathrm{ppb}, \mathrm{VOC}_{0}=480 \mathrm{ppbC}\right)$ and $\mathrm{B}\left(\mathrm{NO} \mathrm{x}_{0}\right.$ reduced by $45 \%$ and $\mathrm{VOC}_{0}$ reduced by $22.5 \%$ from A) under $95-100$ th percentile rank TMA ozone meteorological conditions. Source length $L$ is set to $2 \mathrm{~h}$. (b) $T_{\max }$ (occurrence time of $\mathrm{O}_{3 \max }$ ) changes with distance from sources A and B. (c, d) Isopleth diagrams of $\mathrm{O}_{3 \mathrm{max}}(\mathrm{ppb}$ ) for the normalized distance $D=3$ or $6 \mathrm{~h}$. Points A and B indicate the initial concentrations for panel (a) and (b). Point $\mathrm{C}$ is a crossing point with a regime boundary line.

diagrams of $\mathrm{O}_{3 \max }$ were output by the advection-reaction model for $D=3$ and $6 \mathrm{~h}$ (Fig. 8c and d, respectively). On the diagrams, the line connecting maximum $\mathrm{O}_{3 \max }$ values for each $\mathrm{VOC}_{0}$ (the "ridge line") is defined as the boundary between the VOC-limited regime (above the line) and the $\mathrm{NO}_{\mathrm{x}}$-limited regime (below the line). This boundary is approximately linear and is extrapolated to the origin. Thus, we confirm the similarity of the $\mathrm{O}_{3 \max }$ regime boundary, denoted below, which was similarly established on a Lagrangian basis.

$$
\partial\left[\mathrm{O}_{3 \max }\right] / \partial\left[\mathrm{NOx}_{0}\right] \lesseqgtr 0 \quad \text { if } \quad\left[\mathrm{VOC}_{0}\right] \lesseqgtr \alpha\left[\mathrm{NOx}_{0}\right]
$$

where $\alpha$ is the regime boundary (a constant representing the ratio of $\mathrm{VOC}_{0}$ to $\mathrm{NO}_{\mathrm{x} 0}$ on the boundary).

The regime boundary $(\alpha)$ moves as the normalized distance $D$ increases (e.g., from $\alpha=18.8$ at $D=3 \mathrm{~h}$ to $\alpha=9.7$ at $D=6 \mathrm{~h}$; thus, the boundary line revolves counterclockwise between the isopleth diagrams) together with increasing $\mathrm{O}_{3 \max }$. Therefore, $\alpha$ is clearly an important measure of the progress of photochemical reactions. Decreasing $\alpha$ means
Table 1. Estimated VOC composition of emissions during 05:0015:00 LT in July in the Tokyo Metropolitan Area.

\begin{tabular}{ll}
\hline CBIV species groups & Volume \% \\
\hline PAR (paraffin carbon bond) & 81.77 \\
ETH (ethene) & 1.06 \\
OLE (olefinic carbon bond) & 1.66 \\
TOL (toluene) & 2.67 \\
XYL (xylene) & 2.12 \\
FORM (formaldehyde) & 1.37 \\
ALD2 (high molecular weight aldehydes) & 2.13 \\
ISOP (isoprene) & 2.62 \\
NR (non-reactive) & 4.59 \\
\hline
\end{tabular}

that the $\mathrm{NO}_{\mathrm{x} 0}$ concentration that causes the highest $\mathrm{O}_{3 \max }$ for an arbitrary $\mathrm{VOC}_{0}$ increases continuously with $D$ (dotted line in Fig. 9). As shown in Fig. 9, the rate of increase of $\mathrm{O}_{3 \max }$ with $D$ in the VOC-limited regime near the boundary 


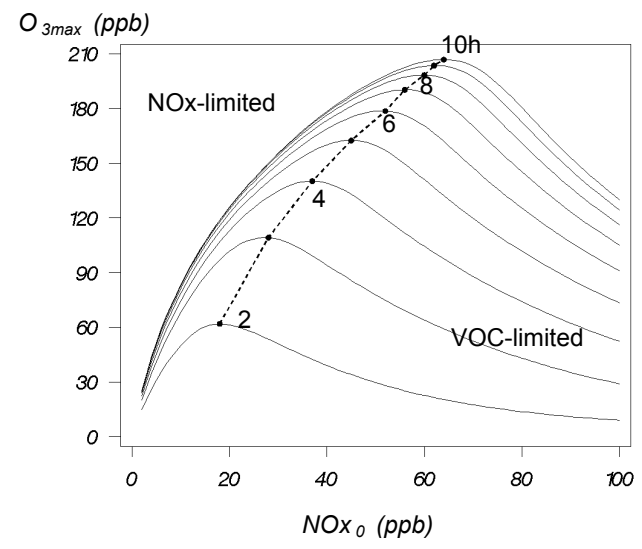

Fig. 9. An example of $\mathrm{O}_{3 \max }$ growth and changes of the regime boundary (denoted by the dashed line) with normalized distance $D$ for an initial VOC concentration of $500 \mathrm{ppbC}(L=2 \mathrm{~h})$.

is high, but in the $\mathrm{NO}_{\mathrm{x}}$-limited regime away from the boundary, the rate of increase of $\mathrm{O}_{3 \max }$ with $D$ becomes low.

\subsection{Spatial reversals of the OWE}

Points A and B in Fig. 8c and d are the plots of the typical weekday and Sunday initial concentrations used in Fig. 8a. It is clear that the OWE is due to a larger reduction in $\mathrm{NO}_{\mathrm{x} 0}$ than in $\mathrm{VOC}_{0}$ both of weekday and Sunday within the VOClimited regime (Fig. 8c); then reversal of the OWE occurs because the change to an $\mathrm{NO}_{\mathrm{x}}$-limited regime occurs earlier on Sundays than on weekdays (Fig. 8d). Therefore, we conclude that the observed spatial reversals of the OWE are signals of a change in the $\mathrm{O}_{3 \max }$ formation regime between weekdays and Sundays in the stream from VOC-limited to $\mathrm{NO}_{\mathrm{x}}$-limited along the transport path from the precursor source.

\subsection{Reversals of the OWE in relation to meteorological conditions}

We also calculated $\mathrm{O}_{3 \max }$ isopleth diagrams for different meteorological conditions (e.g., Fig. 7) with the advectionreaction model. Because the regime boundary is the most important measure of photochemical evolution, we compared the relationship of $\alpha$ with $D$ among these different meteorological conditions (black lines in Fig. 10). For example, if we assume an urban source with $\mathrm{VOC}_{0} / \mathrm{NO}_{\mathrm{x}_{0}}$ of $\sim 15, \mathrm{O}_{3 \max }$ is governed by $\mathrm{NO}_{\mathrm{x}}$-limited chemistry at points more remote than $D=3.7 \mathrm{~h}$ under the $95-100$ th percentile rank meteorology; this regime boundary moves to $D=6.4 \mathrm{~h}$ under the 65-70th percentile rank. Thus, under less suitable meteorological conditions for ozone formation, a longer time (i.e., a longer distance from the source) is required for the change to an $\mathrm{NO}_{\mathrm{x}}$-limited regime. This result directly accounts for the

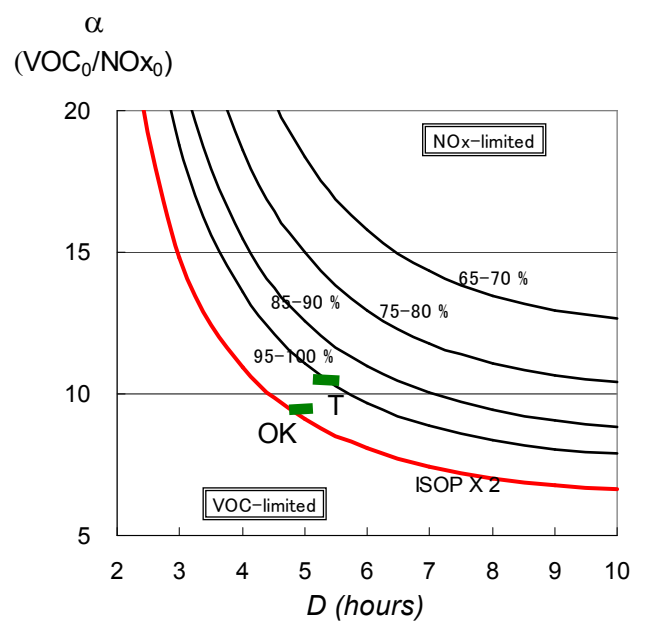

Fig. 10. Changes of regime boundary $\alpha\left(\mathrm{VOC}_{0} / \mathrm{NO}_{\mathrm{x} 0}\right)$ with normalized distance $D$ (hours) under the meteorological conditions of various areal ozone percentile intervals (black lines). The red line shows the boundary for ISOP $=5.24 \%$ of VOCs (instead of $2.62 \%$; Table 1), under 95-100th percentile rank conditions. The two bars are regime boundaries estimated from the observed reversal of the OWE for TMA $(T)$ and the Osaka-Kyoto area $(\mathrm{OK})$ at the 98th percentile rank of $\mathrm{O}_{3 \max }$.

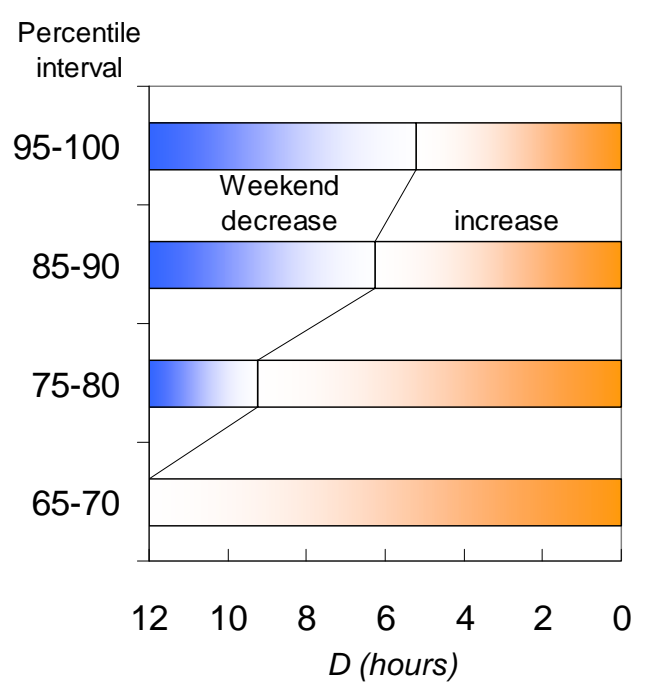

Fig. 11. Changes in the OWE reversal point with normalized distance $D$, simulated for various percentile rank intervals meteorological conditions in the TMA. Initial concentrations of VOC and $\mathrm{NO}_{\mathrm{x}}$ on weekdays and Sundays are those indicated by A and $\mathrm{B}$, respectively, in Fig. 8 ( $\mathrm{VOC}_{0} / \mathrm{NO}_{\mathrm{x} 0}=8$ and 11.3 , respectively).

observation that the reversal of the OWE occurs at more remote points from the source under less suitable meteorological conditions (e.g., Fig. $3 d \rightarrow 3 c \rightarrow 3 b \rightarrow 3 a$ ). The relationship between the change in meteorological conditions and the reversal point of the OWE based on model calculations is diagrammed in Fig. 11 for the initial precursor concentrations 


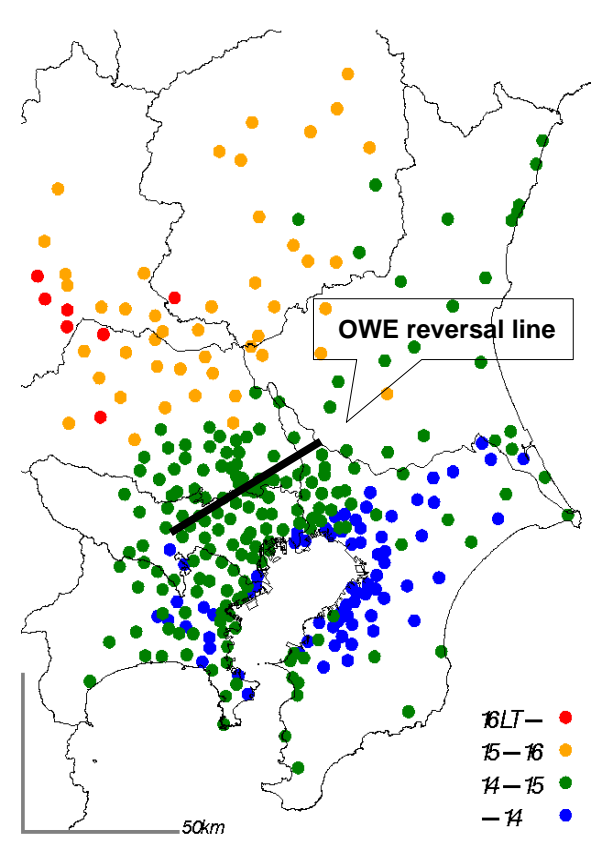

Fig. 12. Mean observed occurrence time of $\mathrm{O}_{3 \max }\left(T_{\max }\right)$ on $95-$ 100th percentile rank weekdays for TMA ozone levels during 19992004. Features on Sundays are similar to those on weekdays. The OWE reversal line is estimated from Fig. 3d.

A (weekday) and B (Sunday, see Fig. 8). The reversal point shifts to more remote points as the meteorological conditions become less suitable for ozone formation (lower percentile rank conditions). Finally, under 65-70th percentile (or less) rank interval conditions, reversal cannot occur within a single transport day with initial precursor concentrations A and B. Thus, for reversal of the OWE to occur, meteorological conditions must be more suitable than some critical level. Though the reversal point may also be changed by changing the assumed initial weekday and Sunday concentrations, the results shown in Fig. 11 clearly indicate that a fundamental relationship exists between meteorological conditions and the OWE reversal point. Moreover, they reveal the fundamental cause of the variation in the number of sites showing the OWE (compare Fig. 11 with Fig. 2).

\section{Discussion}

\subsection{Change of the regime boundary}

The chemical regime boundary $\alpha$, an important measure of the photochemical evolution causing $\mathrm{O}_{3 \max }$ formation that can be estimated from $\mathrm{O}_{3 \max }$ isopleth diagrams, depends mainly on the three parameters listed below.

1. Cumulative solar radiation: $\mathrm{O}_{3 \max }$ at more remote points reflects larger cumulative solar radiation during the transport process; then has lower $\alpha$ value than at points closer to the source (variation along each line in Fig. 10).

2. Intensity of solar radiation: More intense solar radiation accelerates photochemical reactions, thus causing $\alpha$ to decrease more rapidly (the variation among the meteorological conditions shown in Fig. 10).

3. VOC reactivity: We discuss the effect of VOC reactivity only briefly. The red line in Fig. 10 shows the simulated change in $\alpha$ when the isoprene (ISOP; most reactive in CBIV species) percentage in the emitted precursors is doubled (see Table 1), using the 95-100th percentile rank meteorology. This result shows that when the VOC composition has higher reactivity, $\alpha$ decreases more rapidly.

We infer that these parameters affect the observed reversals of the OWE via their effect on the location of the chemical regime boundary. One additional parameter affecting the attainable minimum $\alpha$ in one day's transport is the size of the emission source $L$. The attainable minimum value of $\alpha=7.8$ when $L=2 \mathrm{~h}$ under the 95-100th percentile rank meteorology, changes to $\alpha=8.4$ when $L=4 \mathrm{~h}$. Therefore, the transition to an $\mathrm{NO}_{\mathrm{x}}$-limited regime is less likely to occur in areas downwind from huge sprawling cities than in those downwind of compact cities, for emission sources with the same $\mathrm{VOC}_{0} / \mathrm{NO}_{\mathrm{x} 0}$.

\subsection{Applicability of the model to the real world}

Several studies using three-dimensional numerical chemical transport models have reported a change in the ozone formation regime along the transport path (Milford et al., 1994; Sillman, 1999; Carmichael et al., 2003; Jiménez et al., 2005; Beekmann and Vautard, 2009). In contrast, the advectionreaction model is a semi-quantitative model that uses very simple methodology to show chemical regime changes with the aim of reproducing observed OWE reversals. Because these are very complex phenomena in the real world, we note the applicability of this model in slight detail.

The spatial distribution of the mean observed occurrence time of $\mathrm{O}_{3 \max }\left(T_{\max }\right)$ is shown in Fig. 12 for the 95-100th percentile rank interval days in the TMA. Observed $T_{\max }$ clearly occurs later in inland areas than in coastal areas, by about $1 \mathrm{~h}$ per $30 \mathrm{~km}$, that is, by $(1 / 3$ to $1 / 2) \Delta D(30 \mathrm{~km}$ is equivalent to $D=2-3 \mathrm{~h}$ when $U=3-4 \mathrm{~m} / \mathrm{s}$ in the afternoon; see Fig. 5b). This well-reproduced change is predicted by the advection-reaction model (Fig. 8b), suggesting that the model is applicable in the real world.

The rate at which $\alpha$ changes depends on the rate of elimination of $\mathrm{NO}_{\mathrm{x}}$. A sensitivity analysis of $\mathrm{NO}_{\mathrm{x}}$ dry deposition effects in the advection-reaction model, using $0.1 \mathrm{~cm} / \mathrm{s}$ for $\mathrm{NO}$ and $0.6 \mathrm{~cm} / \mathrm{s}$ for $\mathrm{NO}_{2}$ (Sillman et al., 1998) with a mixing height of $1000 \mathrm{~m}$, revealed that the rate of decrease of $\alpha$ accelerated by about $3 \%$. Therefore, $\mathrm{NO}_{\mathrm{x}}$ elimination by dry 
Table 2. Values of several parameters estimated from the observed reversals of the OWE in the TMA and Osaka-Kyoto areas at the 98th percentile rank of $\mathrm{O}_{3 \max }$.

\begin{tabular}{|c|c|c|c|}
\hline Item & & TMA & Osaka-Kyoto \\
\hline \multirow[t]{2}{*}{ Observed $\mathrm{VOC} / \mathrm{NO}_{\mathrm{x}}$ at $\mathrm{CUC}^{\mathrm{a}}$ during 06:00-09:00 LT (ppbC/ppb) } & weekdays & 8 & 7 \\
\hline & Sundays & 11 & 10 \\
\hline Estimated regime boundary $\alpha$ by the reversal of the OWE (ppbC/ppb) ${ }^{b}$ & $\sim 10.5$ & $\sim 9.4$ & \\
\hline Observed reversal point of the OWE (distance from CUC) ${ }^{\mathrm{c}}$ & $\sim 30 \mathrm{~km}$ & $\sim 15 \mathrm{~km}$ & \\
\hline Observed $T_{\max }$ at the reversal point of the OWE (e.g., Fig. 12) (LT) & $14: 30$ & $14: 15$ & \\
\hline $\begin{array}{l}\text { Advection time } D \text { from the source to the reversal point estimated by } T_{\max } \text {, assuming } \\
L=2 \mathrm{~h} \text { (Fig. } 8 \mathrm{~b} \text { ) }\end{array}$ & $5.2-5.6 \mathrm{~h}$ & $4.8-5.2 \mathrm{~h}$ & \\
\hline Observed $\mathrm{O}_{3 \max }$ at the reversal point & $120-140 \mathrm{ppb}$ & $100-120 \mathrm{ppb}$ & \\
\hline
\end{tabular}

${ }^{a}$ CUC, Coastal Urban Center ${ }^{\mathrm{b}}$ Mean initial VOC/NO $\mathrm{N}_{\mathrm{x}}$ weighted by 0.8 for Sunday and 0.2 for weekdays. ${ }^{\mathrm{c}}$ These values are estimated from Fig. $3 \mathrm{~d}$.

deposition would slightly accelerate the change to an $\mathrm{NO}_{\mathrm{x}}-$ limited chemical regime. In contrast, dilution by diffusion probably does not affect $\alpha$ as long as all species are diluted similarly, which is implied by the similarity of the regime boundary.

These considerations and, in particular, the agreement between the spatial and temporal reversals of the OWE predicted by the model and the observed reversals, suggest that the properties derived by our model - (a) similarity of the regime boundary indicated by $\mathrm{VOC}_{0} / \mathrm{NO}_{\mathrm{x}_{0}}$, and (b) a systematic decrease of $\alpha$ with transport distance - accurately characterize the sensitivity of $\mathrm{O}_{3 \max }$ formation to transport history, meteorology, and VOC reactivity.

One of the simple but interesting results of this study is the fact that the release time of the air mass that brings $\mathrm{O}_{3 \max }$ to a given distance $D$ from the source is earlier in the day for more remote points than for points closer to the source (see Figs. 6 and $8 \mathrm{~b}$ ). This is important information for the development of effective countermeasures against ozone pollution in remote areas, which might include activity controls in urban areas in the very early morning (before at least 09:00 LT for $D>6 \mathrm{~h}$ ).

\subsection{Judgment of ozone formation regime by observation}

Judgment of the ozone formation regime is an important problem in surface ozone studies (e.g., Beekman and Vautard, 2009). Because theoretical analyses suggest that the OWE reversal signals a regime change between weekdays and Sundays, we can utilize the OWE reversal phenomenon to determine the chemical regime. One of the rough judgement is that "the OWE reversed points in inland areas shown in Fig. 3a-d have $\mathrm{NO}_{\mathrm{x}}$-limited property for $\mathrm{O}_{3 \max }$ formation, at least on Sundays" as suggested in Fig. 8d. Further, by using the model properties in our analysis, we can make somewhat more precise determinations.

The estimated values of several parameters in the TMA and the Osaka-Kyoto area are summarized in Table 2. If the observed morning $\mathrm{VOC} / \mathrm{NO}_{\mathrm{x}}$ in a coastal urban center (CUC) is taken as the initial condition, regime boundary $\alpha$ where the reversal of the OWE is observed can be estimated from the weighted mean values of these initial conditions on weekdays and weekends (AC:CB, Fig. 8d, is estimated to be about $8: 2$ by isopleths analysis at the reversed $D$ ): $\alpha=10.5$ for the TMA and 9.4 for the Osaka-Kyoto area at the 98th percentile rank of $\mathrm{O}_{3 \max }$. Roughly estimated distances from the CUC to the inland reversal point of the OWE are about $30 \mathrm{~km}$ and $15 \mathrm{~km}$ for these respective metropolitan areas (Fig. 3d). The observed occurrence time of $\mathrm{O}_{3 \max }$ at the reversal points is 14:30 LT in the TMA (Fig. 12), so the estimated advection time $D$ from the source to the reversal point is $5.2-5.6 \mathrm{~h}$ by the advection-reaction model, if $L=2 \mathrm{~h}$ (Fig. 8 b). Similarly, $D$ can be estimated to be $4.8-5.2 \mathrm{~h}$ in the Osaka-Kyoto area.

These relationships between the estimated $D$ and the observed $\alpha$ are also shown in Fig. 10 and compared with model calculation results. Though $\alpha$ in the TMA agrees well with the model calculations for 95-100th percentile meteorological conditions in the TMA, $\alpha$ decreases more rapidly in the Osaka-Kyoto area than in the TMA. We have not yet performed model calculations for the meteorological conditions in the Osaka-Kyoto area, but we believe that a relatively higher solar intensity (about 10\% higher than in the TMA) might explain the more rapidly decreasing $\alpha$ there.

By using the $\alpha-D$ diagrams, we can estimate the chemical regime for arbitrary values of $D$. For example, under the initial weekday concentrations in the TMA $\left(\mathrm{VOC}_{0} / \mathrm{NO}_{\mathrm{x}_{0}} \sim 8\right)$, the chemical regime is VOC-limited until $D$ of about $8 \mathrm{~h}$ even under extremely suitable meteorological conditions (Fig. 10); thus, a reduction of VOCs or a large reduction in $\mathrm{NO}_{\mathrm{x}}$ beyond the regime boundary is necessary for $\mathrm{O}_{3 \max }$ to be reduced. Needless to say, the chemical regime governing $\mathrm{O}_{3 \max }$ formation is not stable but varies systematically with the transport distance, meteorology, and VOC reactivity.

Thus, although many factors can modify the ozone formation regime in the real world, observation of OWE reversals is one method that can be used to determine ozone formation regimes in further research work. 


\section{Summary}

Over broad areas of Japan, extremely systematic reversals of the ozone weekend effect are observed in hourly monitoring data collected at many observation sites. The important features are (1) spatial reversals from a weekend increase in the vicinity of huge precursor source areas to a weekend decrease in the surrounding rural areas, and (2) temporal reversals from a weekend increase under relatively unsuitable meteorological conditions for ozone formation to a weekend decrease under relatively suitable conditions.

Using a simple advection-reaction model, we estimated the cause of the reversals of the ozone weekend effect to be a shift in the regime boundary in the air mass bringing $\mathrm{O}_{3 \max }$ with distance from the precursor source, with a larger reduction rate of $\mathrm{NO}_{\mathrm{x}}$ weekend emissions than VOC emissions being a necessary condition.

Weekend ozone changes depend on solar intensity as well as on the $\mathrm{VOC} / \mathrm{NO}_{\mathrm{x}}$ ratio of emissions. Daily cumulative solar radiation in the 95-100th percentile rank interval of the TMA ozone level is $21.5 \mathrm{MJ} / \mathrm{m}^{2}$ (Fig. 7, TMA is at $35^{\circ} \mathrm{N}$ ). Big cities and their environs anywhere in the world that experience similar solar intensity to that of the TMA, and where human activities similarly change on weekends, may show a similar reversal of the OWE. For detection of weekend ozone changes, comparison between weekdays and weekends at the same percentile rank of ozone concentration is a simple and useful method because it ensures comparison under similar meteorological conditions.

Furthermore, our theoretical findings indicate that we can determine the ozone formation regime for the daily maximum ozone concentration at a specific location under specific meteorological conditions by observing weekend ozone changes.

Acknowledgements. This work was supported by a cooperative research project ("Study on characteristics of photochemical oxidants and particulate matter") between the National Institute for Environmental Studies and local governmental institutes for environmental research in Japan. We acknowledge the efforts of all the staff members of this project.

Edited by: R. Vautard

\section{References}

Altshuler, S. L., Arcado, T. D. and Lawson, P. K.: Weekday vs. weekend ambient ozone concentrations: Discussion and hypotheses with focus on Northern California, J. Air Waste Manage. Assoc., 45, 967-972, 1995.

Beekmann, M. and Vautard, R.: A modelling study of photochemical regimes over Europe: robustness and variability, Atmos. Chem. Phys. Discuss., 9, 1521-1560, doi:10.5194/acpd-9-15212009, 2009.
Blanchard, C. L. and Fairley, D.: Spatial mapping of VOC and $\mathrm{NO}_{\mathrm{x}}$-limitation of ozone formation in central California, Atmos. Environ., 35, 3861-3873, 2001.

Brönnimann, S. and Neu, U.: Weekend-weekday differences of near-surface ozone concentrations in Switzerland for different meteorological conditions, Atmos. Environ., 31, 1127-1135, 1997.

Carmichael, G. R., Tang, Y., Kurata, G., et al.: Regional-scale chemical transport modeling in support of observations obtained during the TRACE-P experiment, J. Geophys. Res., 108(D21), 8823, doi:10.1029/2002JD003117, 2003.

Cleveland, W. S., Graedel, T. E., Kleiner, B. and Warmer, J. L.: Sunday and workday variations in the photochemical air pollution in New Jersey and New York, Science, 186, 1037-1038, 1974.

Elkus, B. and Wilson, K. R.: Photochemical air pollution: weekendweekday differences, Atmos. Environ., 11, 509-515, 1977.

Fujita, E. M., Stockwell, W. R., Campbell, D. E., Keislar, R. E., and Lawson, D. R.: Evolution of the magnitude and spatial extent of the weekend ozone effect in California's South Coast Air Basin, J. Air Waste Manage. Assoc., 53, 802-815, 2003.

Gery, M. W., Whitten, G. Z., Killus, J. P., and Dodge, M. C.: A photochemical kinetics mechanism for urban and regional scale computer modeling, J. Geophys. Res, 94, 12925-12956, 1989.

Heuss, J. M., Kahlbaum, D. F., and Wolff, G. T.: Weekday/weekend ozone differences: what can we learn from them?, J. Air Waste Manage. Assoc., 53, 772-788, 2003.

Jacob, D. J.: Introduction to atmospheric chemistry, Princeton University Press, 231-244, 1999.

Jenkin, M. E. and Clemitshaw, K. C.: Ozone and other secondary photochemical pollutants: chemical processes governing their formation in the planetary boundary layer, Atmos. Environ., 34, 2499-2527, 2000.

Jiménez, P., Parra, R., Gassó, S., and Baldasano, J. M.: Modeling the ozone weekend effect in very complex terrains: a case study in the Northeastern Iberian Peninsula, Atmos. Environ., 39, 429444, 2005.

Kannari, A.: An analysis of weekend effects on photochemical oxidant concentrations in the Kanto and Kansai regions, Part 1 Finding of two kinds of reversals on weekend effect, in Japanese with English abstract, J. Jpn. Soc. Atmos. Environ. 41(4), 209-219, 2006a.

Kannari, A.: An analysis of weekend effects on photochemical oxidant concentrations in the Kanto and Kansai regions, Part 2 Verification of dynamically changing ozone formation regimes, in Japanese with English abstract, J. Jpn. Soc. Atmos. Environ., 41(4), 220-233, 2006b.

Kannari, A. and Ohara, T.: A mechanism of reversals on the ozone weekend effect, in Japanese with English abstract, J. Jpn. Soc. Atmos. Environ., 44(2), 82-90, 2009.

Kannari A., Tonooka, Y., Baba, T., and Murano, K.: Development of multiple-species $1 \mathrm{~km} \times 1 \mathrm{~km}$ resolution hourly basis emissions inventory for Japan, Atmos. Environ., 41, 3428-3439, 2007.

Milford, J. B., Gao, D., Sillman, S., Blossey, P., and Russel, A. G.: Total reactive nitrogen $\left(\mathrm{NO}_{\mathrm{y}}\right)$ as an indicator of the sensitivity of ozone to reductions in hydrocarbon and $\mathrm{NO}_{\mathrm{x}}$ emissions, $\mathrm{J}$. Geophys. Res., 99(D2), 3533-3542, 1994.

Murphy, J. G., Day, D. A., Cleary, P. A., Wooldridge, P. J., Millet, D. B., Goldstein, A. H., and Cohen, R. C.: The weekend effect within and downwind of Sacramento - Part 1: Observations 
of ozone, nitrogen oxides, and VOC reactivity, Atmos. Chem. Phys., 7, 5327-5339, doi:10.5194/acp-7-5327-2007, 2007.

Murphy, J. G., Day, D. A., Cleary, P. A., Wooldridge, P. J., Millet, D. B., Goldstein, A. H., and Cohen, R. C.: The weekend effect within and downwind of Sacramento: Part 2. Observational evidence for chemical and dynamical contributions, Atmos. Chem. Phys. Discuss., 6, 11971-12019, doi:10.5194/acpd6-11971-2006, 2006.

Paschalidou, A. K. and Kassomenos, P. A.: Comparison of air pollutant concentrations between weekdays and weekends in Athens, Greece for various meteorological conditions, Environ. Technol., 25, 1241-1255, 2004.

Pun, B. K. and Seigneur, C.: Day-of-week behavior of atmospheric ozone in three U.S. cities, J. Air Waste Manage. Assoc., 53, 789801, 2003.
Sillman, S.: The relation between ozone, $\mathrm{NO}_{\mathrm{x}}$ and hydrocarbons in urban and polluted rural environments, Atmos. Environ., 33, 1821-1845, 1999.

Sillman, S., He, D., Pippin, M., Daum, P., Kleinman, L., Lee, J. H., and Weinstein-Lloyd, J.: Model correlations for ozone, reactive nitrogen and peroxides for Nashville in comparison with measurements: implications for VOC-NO $\mathrm{NO}_{\mathrm{x}}$ sensitivity. J. Geophys. Res. 103, 22629-22644, 1998.

Stephens, S., Madronich, S., Wu, F., Olson, J. B., Ramos, R., Retama, A., and Muñoz, R.: Weekly patterns of México City's surface concentrations of $\mathrm{CO}, \mathrm{NO}_{\mathrm{x}}, \mathrm{PM} 10$ and $\mathrm{O}_{3}$ during 19862007, Atmos. Chem. Phys., 8, 5313-5325, doi:10.5194/acp-85313-2008, 2008. 